\title{
Women's Work: Why Are Women Physicians More Burned Out?
}

Katherine J. Gold, MD, MSW, MS

(J Am Board Fam Med 2020;33:351-354.)

A woman family physician in rural practice recently commented to me: "My male colleague did not even know my patient had depression, but that is all she wants to talk about with me." A colleague in academic family medicine echoed a similar perspective: "Well of course female physicians are burned out; we deal with the emotional needs, and the staff are more likely to page me, than my male colleagues, at home with a patient question or ask me to do a task after hours."

In this issue of the Fournal of the American Board of Family Medicine, Eden et $\mathrm{al}^{1}$ provide a specialtyspecific view on burnout among family physicians, with a focus on age and gender. The researchers surveyed a large population of family medicine physicians by using 2 questions assessing burnout. In all age categories, women were more likely to report emotional exhaustion and in most age categories were more likely to endorse callousness. The effect was particularly striking in physicians under age 40. A considerable body of research has now highlighted the high levels of burnout among physicians generally, with increased rates among women physicians ${ }^{2-6}$ and for younger physicians in general. $^{7}$

Women make up $54 \%$ of family medicine residents now in training ${ }^{8}$ and comprise an increasing proportion of the family medicine workforce. To

From Department of Family Medicine and Department of Obstetrics and Gynecology, University of Michigan

Funding: No funding was provided for this study

Conflicts of interests: The author has no conflicts of interest to declare.

Corresponding author: Katherine J. Gold, MD, MSW, MS, University of Michigan. 1018 Fuller Street, Ann Arbor, MI 48104-1213, Phone: 734-998-2449, Fax: 734-998-7335 (E-mail:ktgold@umich.edu).

\section{See Related Article on Page 355.}

boost satisfaction and sustainability of family medicine careers, we need to think deeply about how the experience of being a physician differs by age and gender (as well as race, nationality, language, and other identity-related variables beyond the scope of this study). The good news is that many health systems have recognized that individual "fixes" for burnout fail to address the dysfunctions of the health care structure that cause the underlying stress. However, the data in this article underscore individual variation in burnout, and universal interventions may not provide the same benefits to all. There may be unique elements that make some interventions more or less impactful for the physician cohorts at highest risk.

Women face ubiquitous challenges in the workforce, which reduce job satisfaction. Women earn lower salaries, and although physicians are highly compensated compared with many professions, the gender disparities in salary are still prominent. ${ }^{9}$ Women physicians experience more harassment and mistreatment, not only from staff and colleagues but also from patients. ${ }^{10}$ In an online Facebook group for women physicians who are parents, 1 woman explained how she tries to fit in the word "physician" at least 3 times during a patient visit so that the patient recognizes that they were indeed seen by a doctor. Others describe experimenting with their Press Ganey patient satisfaction scores and report getting higher scores if they wear glasses to work or put their hair into a more conservative hairdo. Women of color on the site frequently share experiences of being mistaken for housekeeping staff, often despite wearing physician name badges and white coats.

Women in all fields experience the career consequences of decisions about fertility and childbearing, but this may be particularly consequential 
in medicine due to the duration and intensity of training. ${ }^{11}$ In dual-career families, women spend more time on "mental labor"-work planning and coordinating every day family tasks-which is often not considered when assessing home responsibilities. ${ }^{12}$ During the COVID-19 pandemic, women physicians may manage more of the unseen mental burden of children at home and household planning while they continue to work.

Conflicts in balancing work and home responsibilities contribute to the gender differences in physician burnout; while these may impact mental health and stress, they do not fully explain burnout. ${ }^{13,14}$ Control over workload is a driving factor in burnout across professions. ${ }^{15-18}$ However, the relationship between family life and satisfaction with work/life balance is more complex. A study at an academic medical center reported having children under 18 at home slightly reduced career satisfaction for clinical faculty and increased satisfaction for nonclinical faculty, but this surprisingly did not differ by age, gender, marital status, or selfreported family demands. ${ }^{19}$ Among Canadian family physicians, women were more likely than men to be satisfied with work/life balance, even controlling for age and number of hours worked. ${ }^{14}$

Anecdotal comments about variations in patient interactions are backed by the limited research in this area. First, women make more ambulatory care office visits, ${ }^{20}$ and women physicians see more female patients than their male colleagues. ${ }^{16,21,22}$ Same-gender visits (eg, male physician and male patient or vice versa) are slightly longer than different-gender visits, in primary care and other settings. $^{22,23}$ Gender also influences the content of medical visits. Female patients are twice as likely to raise emotional content with female versus male physicians, which may subsequently contribute to longer visits. ${ }^{16,24}$ In addition, lack of time for patient relationships has been shown to be more important for women physicians. ${ }^{5}$

It is worth considering the overlap between symptoms of burnout and depression, as women have higher rates of depression. However, these are distinct phenomena, with burnout being limited to the work setting and depression not accounting fully for the gender differences. ${ }^{25}$ Mental health care and help-seeking should be less stigmatized for all physicians but will not eliminate the problem of burnout. The overlap has contributed to disagreement about the construct of burnout and how best to define and assess burnout among physicians. ${ }^{26,27}$ Family physicians are taught that depression in men may sometimes present as irritability or anger and look different from symptoms of depression in women. Perhaps the presentation of burnout also differs by gender. When researchers measure burnout with very brief surveys, they may not capture the same constructs among different subsets of physicians and may miss nuanced variations.

Electronic health records offer practice benefits, but the omnipresent demands of computer documentation pull us from casual interactions with our colleagues, while minimizing opportunities for informal peer support and mentoring. As women in medicine are more likely than their male colleagues to have a partner who works full-time, ${ }^{28}$ being efficient at work becomes a necessity to preserve time for household tasks and parenting. The electronic health medical record threatens to dilute the relationship focus of our specialty, which may feel particularly incongruous for many women physicians. ${ }^{5}$ These are the insidious losses that come from well-intentioned attempts to improve patient care efficiency.

Although there is research exploring gender in physician-patient communications, there is minimal data on physician-staff interactions. Despite growing diversity, medical support staff (nurses, medical assistants, and clerical staff) still are disproportionately women. How do interactions with staff vary for men and women physicians? Are physicians of both genders offered similar amounts of help, treated with similar respect, and provided similar clinic support? Do interactions impact gender differences in physician satisfaction or burnout in positive or negative ways?

The 2 groups included in the study highlighted here $^{1}$ included a cohort 3 years out of residency (the entire under-40 group) and a similarly-sized group with a far broader range of career experience (but age over 40). It is plausible that burnout assessed at 3 years into practice or fellowship may be particularly pronounced and explain age-related differences. This might reflect physical moves, growth of families, financial strains including student loan burdens, or the reality of adjusting to new jobs. There could be other unmeasured factors beyond age and gender, which are more significant drivers of burnout, or perhaps burnout in younger physicians also has a slightly different phenotype.

This $7 A B F M$ article by Eden et $\mathrm{al}^{1}$ reinforces that burnout among women family physicians 
continues to be of concern. Family medicine researchers should lead the way in investigating the etiology of these differences and advocate for work improvements. Scheduling flexibility and timebased billing allow more autonomy to adapt to different clinician needs and preferences. Better administrative support gives physicians more faceto-face patient care time, which might disproportionally reduce stress for women. Recognizing that male and female physicians see somewhat different populations and engage in different clinical content is critical to support good patient relationships for both genders.

The profession as a whole must continue to address systemic inequities to ensure the workplace is equitable and welcoming as our workforce continues to diversify. Finding ways to promote interpersonal peer interactions is also important, even if done through virtual gatherings to promote social distancing. This may be especially critical during the current times of great uncertainty and overwhelming stress among health care workers in light of the COVID-19 pandemic. Innovative thinkers have explored the idea of medicine as a "calling" as this seems to protect against burnout and dissatisfaction. ${ }^{29-31}$ Although this does not vary by gender, it is an important value to support among family physicians. Given the real human and economic risks from burnout for health care clinicians, ${ }^{32}$ we have an urgent need to understand how burnout varies for men and women and to design interventions that specifically respond to these needs.

To see this article online, please go to: bttp://jabfm.org/content/ 33/3/351.full.

\section{References}

1. Eden AR, Jabbarpour Y, Morgan ZJ, et al. Gender differences in personal and organizational mechanisms to address burnout among family physicians. J Am Board Fam Med 2020;33:446-451.

2. Amoafo E, Hanbali N, Patel A, Singh P. What are the significant factors associated with burnout in doctors? Occup Med 2015;65:117-21.

3. Baptiste D, Fecher AM, Dolejs SC, et al. Gender differences in academic surgery, work-life balance, and satisfaction. J Surg Res 2017;218:99-107.

4. Rabatin J, Williams E, Baier Manwell L, Schwartz MD, Brown RL, Linzer M. Predictors and outcomes of burnout in primary care physicians. J Prim Care Community Health 2016;7:41-3.
5. Rizvi R, Raymer L, Kunik M, Fisher J. Facets of career satisfaction for women physicians in the United States: a systematic review. Women Health 2012;52:403-21.

6. Weidner AKH, Phillips RL, Jr., Fang B, Peterson LE. Burnout and scope of practice in new family physicians. Ann Fam Med 2018;16:200-5.

7. Del Carmen MG, Herman J, Rao S, et al. Trends and factors associated with physician burnout at a multispecialty academic faculty practice organization. JAMA Netw Open 2019;2:e190554.

8. American Association of Medical Colleges. 2019 report on residents. Available from: http://www.aamc. org/data-reports/students-residents/interactive-data/ report-residents/2019/table-b3-number-activeresidents-type-medical-school-gme-specialty-and-sex. Accessed March 15, 2020

9. Jena AB, Olenski AR, Blumenthal DM. Sex differences in physician salary in US public medical schools. JAMA Intern Med 2016;176:1294-304.

10. Jagsi R, Griffith KA, Jones R, Perumalswami CR, Ubel P, Stewart A. Sexual harassment and discrimination experiences of academic medical faculty. JAMA 2016;315:2120-1.

11. Stentz NC, Griffith KA, Perkins E, Jones RD, Jagsi R. Fertility and childbearing among American female physicians. J Womens Health (Larchmt) 2016;25:1059-65.

12. Offer $\mathrm{S}$. The costs of thinking about work and family: mental labor, work-family spillover, and gender inequality among parents in dual-earner families. Sociol Forum 2014;29:916-36.

13. Dishon-Berkovits M. Burnout: contributing and protecting factors within the work-family interface. J Career Dev 2014;41:467-86.

14. Malhotra J, Wong E, Thind A. Canadian family physician job satisfaction-is it changing in an evolving practice environment? An analysis of the 2013 National Physician Survey database. BMC Fam Pract 2018;19:100.

15. Frank E, McMurray JE, Linzer M, Elon L. Career satisfaction of US women physicians: results from the Women Physicians' Health Study. Society of General Internal Medicine Career Satisfaction Study Group. Arch Intern Med 1999;159:1417-26.

16. McMurray JE, Linzer M, Konrad TR, Douglas J, Shugerman R, Nelson K; the SGIM Career Satisfaction Study Group. The work lives of women physicians: results from the physician work life study. J Gen Intern Med 2000;15:372-80.

17. Rassolian M, Peterson LE, Fang B, et al. Workplace factors associated with burnout of family physicians. JAMA Intern Med 2017;177:1036-8.

18. Kumar S. Burnout and doctors: prevalence, prevention and intervention. Healthcare 2016;4:37.

19. Beckett L, Nettiksimmons J, Howell LP, Villablanca AC. Do family responsibilities and a clinical 
versus research faculty position affect satisfaction with career and work-life balance for medical school faculty? J Womens Health (Larchmt) 2015; 24:471-80.

20. Ashman JJ, Rui P, Titilayo O. Characteristics of office-based physician visits, 2016. Hyattsville (MD): National Center for Health Statistics; 2019.

21. Bertakis KD. The influence of gender on the doctor-patient interaction. Patient Educ Couns 2009; 76:356-60.

22. Franks P, Bertakis KD. Physician gender, patient gender, and primary care. J Womens Health (Larchmt) 2003;12:73-80.

23. Sandhu H, Adams A, Singleton L, Clark-Carter D, Kidd J. The impact of gender dyads on doctorpatient communication: a systematic review. Patient Educ Couns 2009;76:348-55.

24. Tabenkin H, Goodwin MA, Zyzanski SJ, Stange $\mathrm{KC}$, Medalie JH. Gender differences in time spent during direct observation of doctor-patient encounters. J Womens Health (Larchmt) 2004;13:341-9.

25. Eckleberry-Hunt J, Kirkpatrick H, Taku K, Hunt R. Self-report study of predictors of physician wellness, burnout, and quality of patient care. South Med J 2017;110:244-8.
26. Rotenstein LS, Torre M, Ramos MA, et al. Prevalence of burnout among physicians: a systematic review. JAMA 2018;320:1131-50.

27. Schwenk TL, Gold KJ. Physician burnout-a serious symptom, but of what? JAMA 2018;320: 1109-10.

28. Shollen SL, Bland CJ, Finstad DA, Taylor AL. Organizational climate and family life: how these factors affect the status of women faculty at one medical school. Acad Med 2009;84:87-94.

29. Jager AJ, Tutty MA, Kao AC. Association between physician burnout and identification with medicine as a calling. Mayo Clinic Proc 2017;92: 415-22.

30. Tak HJ, Curlin FA, Yoon JD. Association of intrinsic motivating factors and markers of physician well-being: a national physician survey. J Gen Intern Med 2017;32:739-46.

31. Yoon JD, Daley BM, Curlin FA. The association between a sense of calling and physician well-being: a national study of primary care physicians and psychiatrists. Acad Psychiatry 2017;41:167-73.

32. Shanafelt T, Goh J, Sinsky C. The business case for investing in physician well-being. JAMA Intern Med 2017;177:1826-32. 